\title{
Atividades Físicas em instituições de ensino infantil: uma abordagem bioecológica
}

\author{
Games and playthings in a child day care center: a bioecological \\ approach
}

\footnotetext{
1 Universidade Metodista de Piracicaba. Programa de Pós-Gradução em Educação Física. Piracicaba, SP. Brasil.
}

Recebido em 07/02/09 Revisado em 11/05/09 Aprovado em 23/06/09
Resumo - Mudanças sociais têm contribuído para a diminuição de oportunidades para as crianças praticarem atividades físicas; crianças têm sido levadas para instituições de ensino infantil, onde as oportunidades de brincar são insuficientes, perdendo benefícios que tal prática pode trazer. $\mathrm{O}$ objetivo deste estudo foi analisar a relação entre atividades físicas lúdicas e o desenvolvimento infantil. Trata-se de um estudo descritivo que observou 68 crianças de ambos os sexos, entre 4 e 6 anos de idade, de uma Instituição de Ensino Infantil em uma cidade do interior de São Paulo. Um programa com jogos e brincadeiras foi oferecido duas vezes por semana e foi realizado um evento com outras crianças. Foram analisadas atividades, papéis sociais, relações interpessoais, emoções e características pessoais. Houve evolução nas relações interpessoais e desenvolvimento de relações sociais, bem como, do controle emocional. As principais emoções básicas foram expressas e também diversas características das crianças. Assim, introduzir jogos e brincadeiras na escola pode contribuir para o desenvolvimento e engajamento infantil em atividades físicas.

Palavras-chave: Jogos e Brinquedos; Desenvolvimento Infantil; Meio Ambiente; Creches.

Abstract - Social changes have contributed to decreased opportunities for children to perform physical activities. Children have been introduced in preschools where the opportunities of playing are insufficient, thus being deprived of the benefits of such activity. The aim of this study was to analyze the relationship between ludic physical activities and child development. A descriptive study was conducted on 68 children of both genders, aged 4 to 6 years, from a public child day care center. A physical education program was offered twice per week and an event involving other children was carried out. Activities, social roles, interpersonal relations, emotions, and personal characteristics were analyzed. Improvement was observed in interpersonal relations and social relationships, as well as in emotional control. Basic emotions and different child characteristics were expressed. Thus, the introduction of games and playthings at school may contribute to child development and to the engagement of children in physical activities.

Key words: Games and Playthings; Child Development; Environment; Child Day Care Centers. 


\section{INTRODUÇÃO}

Mudanças na sociedade têm alterado, de modo significativo, o estilo de vida das crianças, diminuindo suas possibilidades de movimento, em decorrência do aumento de tráfego urbano, da crescente violência nas ruas, da diminuição de espaços públicos ou privados para brincar ${ }^{1}$. Desde o início do século $X X$, durante o processo de industrialização, várias crianças foram encaminhadas para as chamadas creches, instituições de caráter assistencialista e filantrópico, para auxiliar na solução de problemas sociais, tais como alimentação e cuidados de crianças, cujas mães ingressaram no mercado de trabalho².

Posteriormente, acreditando-se que participar de pré-escola desde a mais tenra idade poderia aumentar as possibilidades de aprendizagem de habilidades acadêmicas, foram criados, em muitos países, programas de educação infantil ${ }^{3}$, levando crianças de diferentes condições sociais para a escola, tornando-se este ambiente um espaço primordial para o desenvolvimento ${ }^{4}$.

Porém, muitas destas instituições ainda exercem apenas o papel de alimentar e cuidar das crianças, diminuindo ainda mais as possibilidades da criança de brincar ${ }^{4}$, o que pode prejudicar o desenvolvimento infantil, pois nesta faixa etária as crianças estão, primeiramente, envolvidas em aprender e a se mover eficientemente, e quanto mais desenvolvem habilidades do movimento melhor exploram, investigam e conhecem o mundo à sua volta. É através da linguagem e do movimento voluntário que a criança pode tornar-se autônoma e desafiadora ${ }^{4}$.

Desde a Educação Infantil, ano a ano de forma crescente, a educação é estruturada para que a criança vá se acostumando a permanecer parada, desrespeitando o modo de ser infanti $1^{4}$. Mesmo assim, a criança procura oportunidades para brincar e se movimentar, por causa do prazer que o brincar traz.

O direito de brincar da criança está assegurado, legalmente, na Constituição, na Declaração dos Direitos da Criança e no Estatuto da Criança e do Adolescente ${ }^{1}$, contudo, nem todas as escolas investem no aprendizado, envolvendo o lúdico. Nas instituições de ensino infantil, embora o alvo desta modalidade de ensino seja o pleno desenvolvimento infantil e seja explicitado o direito das crianças a brincar, reconhecendo-se esta ação como uma forma de comunicação e interação, ainda não existe a obrigatoriedade de um profissional de Educação Física nesta modalidade de ensino.

Sendo assim, jogos e brincadeiras são propostos por diferentes profissionais, muitos ainda não qualificados, como babás e monitores, os quais, na maioria das vezes, não conseguem propiciar um ambiente apropriado para o desenvolvimento infantil, por meio destas atividades, mas existe necessidade de espaços adequados para a criança brincar e profissionais qualificados.

Mas não basta apenas oferecer o espaço adequado, é imprescindível que as vozes das crianças, vistas como sujeitos autores e atores, estejam presentes, incluídas nas decisões que se referem à organização do tempo e espaço da instituição e de suas vidas.

Através de jogos e brincadeiras a criança interage com o meio ambiente e isto se dá pela interação de quatro elementos indissociáveis: o processo, que envolve formas particulares de interação entre o organismo e o ambiente; a pessoa, cujas propriedades incluem as características pessoais; o contexto, composto pelo micro, meso, exo e macrossistema e o tempo, que é um elemento que considera duas dimensões, o período vital e o período social ${ }^{5}$.

Considera-se que a pessoa em desenvolvimento é influenciada direta ou indiretamente por todos os níveis de ambiente do contexto, sendo o microssistema o ambiente imediato que comporta alguns elementos ou blocos construtores que são divididos em: atividades, papéis sociais e relações interpessoais $^{6}$. Estes elementos permitem que a pessoa interaja frente às características físicas e sociais particulares que podem encorajar ou inibir a interação com o meio ambiente? ${ }^{7}$. Esta interação pode ser influenciada por disposições, recursos e demandas pessoais e isto pode favorecer ou não seu desenvolvimento ${ }^{8}$; ela também auxilia a pessoa a, progressivamente, realizar atividades mais complexas para responder às demandas ambientais? mas para que ocorra aderência a esta prática não basta que a pessoa tenha disposição geradora para engajar-se nela, pois outras forças do contexto tais como o intervalo de tempo entre os eventos, a duração destes ou seus resultados, podem enfraquecer ou fortalecer a disposição pessoal ${ }^{10}$.

A disposição em participar ou não em uma atividade está relacionada com o significado que esta tem para a pessoa. Quando a atividade é importante e é realizada com persistência temporal e significado constitui-se em uma manifestação primordial da pessoa (atividades molares) ao passo que atividades insignificantes não apresentam persistência temporal (atividades moleculares) ${ }^{11}$

Estudos sobre a interação da criança com o meio ambiente mostraram que este pode favorecer o desenvolvimento, permitindo manifestação de atributos pessoais e o desempenho de papéis sociais 
que podem auxiliar em seu desenvolvimento $8,12,13$. Porém, pouco se sabe como isto ocorre durante jogos e brincadeiras.

As crianças que vão mais cedo à escola e que estão perdendo os espaços para se movimentar e brincar, poderiam ter, dentro da própria Instituição Infantil, vivências em atividades físicas lúdicas, proporcionando o brincar coletivo, com ações livres e marcadas pela presença da fantasia e da improvisação (brincadeiras) e com a presença de regras (jogos), mas há poucos estudos sobre isto, embora esteja sendo debatida a necessidade de inserção de aulas de Educação Física neste nível escolar, para prevenir doenças associadas ao sedentarismo e a obesidade $^{14,15}$, o que pode dificultar a realização de tarefas motoras ${ }^{16,17}$.

Sendo assim, o objetivo deste estudo foi analisar a relação entre atividades físicas lúdicas e o desenvolvimento infantil.

\section{PROCEDIMENTOS METODOLÓGICOS}

Trata-se de um estudo descritivo, com base na Teoria Bioecológica de Bronfenbrenner ${ }^{8,9}$, que observou 68 crianças de ambos os sexos, entre quatro e seis anos, frequentadoras de uma instituição de ensino no interior de São Paulo. O estudo foi aprovado pelo comitê de ética em pesquisa de uma instituição de ensino superior, com parecer n ${ }^{\circ}$ 61/06 e os responsáveis pelas crianças assinaram o Termo de Consentimento Livre e Esclarecido.

Características do contexto onde ocorreu o estudo foram observadas através de um documento fornecido pela direção local, no qual constavam informações sobre o quadro de funcionários e sobre as atividades propostas, rotineiramente, pela escola, às crianças.

As crianças deste estudo permaneciam entre nove e 10 horas na instituição, sendo o horário de chegada às 700 h e saída entre 16 e 17 h. Trata-se de uma instituição municipal, que atende crianças em tempo integral, com 10 professores/monitores, sendo que um possuía Magistério, três possuíam graduação em Pedagogia, quatro estavam cursando Pedagogia e dois possuiam Ensino Fundamental incompleto.

A rotina das crianças incluia: chegar à escola e esperar pelo início da aula, fazer a refeição matinal, escovar os dentes, participar de uma roda de conversa, ir ao parque (30 minutos), tomar banho, almoçar, escovar os dentes, dormir, tomar leite, ouvir história ou música, jantar, escovar os dentes e esperar que seu responsável viesse buscá-la. As crianças eram distribuídas em salas pequenas de aula, por faixa etária e lá permaneciam, a maior parte do tempo, sentadas, sendo poucos os equipamentos existentes na escola para as crianças realizarem atividades físicas.

Foram observados dois microssistemas: as aulas de Educação Física e um evento lúdico, que foi realizado em outro local e com a participação de outras crianças que não pertenciam ao primeiro microssistema. A interação da criança nos dois microssistemas foi considerado como mesossistema.

Em ambos microssistemas, foram coletados dados sobre as atividades realizadas, relações interpessoais estabelecidas, papéis sociais desempenhados, recursos, disposições (características pessoais), demandas (qualidades para encorajar ou desencorajar reações de outras pessoas) e emoções vivenciadas.

Nas aulas, estes dados foram registrados através de um diário de campo ${ }^{18}$, por um dos pesquisadores e um monitor e foram, posteriormente, transcritos para uma tabela virtual, que permitiu a visualização de cada um destes itens, em cada uma destas crianças ao longo do tempo (mesotempo). Foram realizadas duas aulas semanais, com duração de 40 minutos cada, totalizando 30 sessões.

No evento, estes mesmos dados foram coletados por meio de gravação de imagens das crianças em atividade, feitas com cinco filmadoras; sendo quatro fixadas em um tripé, na diagonal do espaço reservado para cada estação. A outra câmera era móvel e coletava imagens aleatoriamente. As imagens foram transferidas para um computador com software Pinaclle Studio-Movie Box, 9.4, para tratamento das imagens. A observação destas imagens foi feita por dois observadores e permitiu o preenchimento de uma tabela semelhante à montada para visualização da evolução das aulas.

Para o evento, as crianças foram divididas em grupos, aleatoriamente, sendo dirigidas para quatro estações: Pega-Pega com o Tarzan e o Zorro, Passeio na Floresta, Amigos do Peter Pan e Lixo Mal. As crianças foram divididas em equipes com cores diferentes e cada atividade teve a duração de 20 minutos. Ao sinal, uma pessoa auxiliava as crianças a trocarem de estação. $\mathrm{O}$ intervalo de tempo gasto nas trocas de estação foi de cinco minutos.

No Pega-pega com o Tarzan e o Zorro, os monitores reuniram o grupo e explicaram que o Zorro estaria tentando capturar o Tarzan e que as crianças precisariam ajudá-lo. O Passeio na Floresta foi realizado no parque, onde as crianças brincaram no gira-gira, que foi considerado uma super-máquina, que os levou à floresta com diversos obstáculos: subir no escorregador, caminhar sobre o banco, desviar dos balanços, caminhar equilibrando-se 
sobre a corda (ponte no chão), atravessar o trepatrepa até chegar ao tesouro escondido; lá as crianças ganharam um chapéu de jornal.

Na estação do Peter Pan, as crianças receberam uma capa de TNT, uma espada de jornal e uma bexiga, a qual era amarrada no braço da criança. A atividade proposta foi a de tentar estourar a bexiga do colega com a espada e depois caminhar sobre algumas linhas demarcadas no chão. A estação do Lixo Mal trouxe a proposta de cuidar do espaço onde elas estavam brincando. Foi pedido para que as crianças se sentassem, formando um círculo; enquanto elas conversavam, o Lixo Mal chegou jogando jornais amassados no chão. Foi pedido que as crianças ajudassem a chamar o Protetor da Natureza para juntos limparem o local, colocando todo o jornal no cesto do lixo, mas o Lixo Mal insistia em sujar tudo novamente, então, o Protetor da Natureza, junto com as crianças, conversaram com o Lixo Mal e ele passou a ajudar na limpeza.

\section{RESULTADOS}

Durante as aulas foram vivenciados 15 jogos e brincadeiras diferentes, utilizando materiais como: lenços coloridos de TNT, tubos de papelão, bolas e pneus, além de atividades com habilidades motoras básicas. Ao longo das sessões, as seguintes atividades passaram a ser primordiais (molares) para as crianças, pois elas se envolveram cada dia mais com as mesmas e solicitavam sua execução nas aulas: pega-pega rabinho, tapete mágico, lenço atrás, acorda seu urso, gato e rato, pega-pega ajuda, equilibristas, corrida de lenços, corrida de revezamento e corrida de cavalinhos. Nestas atividades, foi observado o maior número de papéis sociais desempenhados pelas crianças, a saber: Personagens de histórias, Fugitivo, Pegador, Motorista, Caçador, Piloto de Fórmula I, Cavaleiro, Equilibrista, Pintor e Jogador de Futebol.

No início do programa, as crianças apresentaram dificuldade em entender que as regras eram para todos; em muitos momentos, cobravam da professora o cumprimento dessas regras por parte de seus colegas, mas em contrapartida não as cumpriam. Algumas crianças chegavam a se afastar das atividades por não aceitar o que fora combinado, outras vezes se tornavam agressivas. Com o passar dos dias, as crianças sugeriram modificações nas regras e passaram a acatá-las. As regras referiamse à delimitação do espaço da atividade, uso do material, atividades permitidas ou não, no jogo e convivência com o outro (ex: ajudar o amigo, comandar a atividade, não empurrar, não beliscar, não morder, não puxar a camiseta, entre outras) .

A maioria das emoções básicas foi manifestada em quase todas as atividades alguma vez por, pelo menos, três crianças. As emoções predominantes foram as de alegria, apresentada pela maioria das crianças em todas as atividades. Porém, emoções de raiva e tristeza também estiveram presentes em muitas sessões, nos diferentes jogos, sendo mais frequentes e exacerbadas nas primeiras aulas, nas quais o medo, também, foi apresentado por uma ou duas crianças, mas com o passar dos dias esta emoção passou a ser menos frequente e, nas últimas tentativas, não apareceu mais. Assim, no mesotempo, as crianças passaram a expressar suas emoções de maneira mais amena, evidenciando aquisições de controle emocional.

Nas aulas iniciais, foram observadas poucas relações interpessoais classificadas em díadas (duas pessoas que interagem), tríadas e pêntadas de observação. Com o passar dos dias, estas relações evoluíram para participação conjunta e tornaramse mais constantes e outras inter-relações foram surgindo e evoluindo.

As demandas observadas, durante algumas atividades, ocorreram quando algumas crianças se destacaram pela liderança. As crianças que foram observadas como líderes positivos demonstraram disposições geradoras, incentivando outras crianças a participarem da atividade; a curiosidade em participar de atividades novas também colaborou para demonstração dessas disposições. As disposições disruptivas passivas foram observadas quando as crianças perderam o interesse na atividade e, algumas vezes, pediram para sentar. As disposições disruptivas ativas foram observadas em momentos em que algumas crianças se mostraram agressivas, ansiosas e egocêntricas, não dando oportunidade para outras crianças participarem do jogo.

No evento, a estação "Passeio na Floresta", não foi de interesse da maioria das crianças que preferiram explorar os materiais ao invés de realizar as atividades propostas, não aceitando bem as regras propostas. Nas outras estações, as crianças participaram dos jogos, colaborando com as regras estabelecidas e depois manifestaram interesse em criar novas formas de brincar e explorar o material oferecido, inclusive, sugerindo regras para sua utilização.

As emoções básicas foram manifestadas pelas crianças: surpresa foi observada no início do evento, quando as crianças observaram mudanças significativas no ambiente, tais como a troca de posição de materiais e equipamentos cotidianos e com a presença de novos materiais e personagens. A alegria 
foi encontrada em todas as crianças, na maior parte do tempo, porém houve momentos em que o medo, também, pôde ser observado, relacionando-se com o contato com um dos personagens (lixo mal). Expressões de raiva, tristeza e ansiedade ocorreram na transição entre uma estação e outra.

Os papéis sociais assumidos pelas crianças foram: fugitivos, pegadores, protetores da natureza, lutadores, super-homem e outros personagens de histórias infantis.

As inter-relações sociais ocorridas foram, em sua maioria, com as crianças oriundas da classe, onde realizavam o programa, sendo 29 Díadas de Participação Conjunta (DPC) e 24 Díadas de Observação (DO), com as outras crianças foram observadas apenas cinco DO, três DPC e 2 tríades de PC.

Disposições disruptivas foram encontradas em várias crianças na sessão Passeio na Floresta, algumas crianças tentaram impedir outras de terem acesso ao equipamento; outras crianças mostraram disposições geradoras (iniciativa e autonomia) e demandas positivas (afeto e convites) e atraíram outras para realizar atividades com os equipamentos. Nas outras estações, foram observadas demandas positivas (manifestação de afeto e cuidado pelos outros).

\section{DISCUSSÃO}

As características do contexto, onde ocorreu o estudo, mostram que as possibilidades previstas para que as crianças realizem atividades físicas na escola eram poucas, não havia profissionais especialistas em movimento, as crianças permaneciam muito tempo em salas pequenas e com poucos equipamentos que estimulassem o seu desenvolvimento, e um adulto que organizava o tempo e dirigia as ações realizadas pelas crianças, nestes espaços, como ocorre, também, em outras instituições de ensino ${ }^{19}$.

Para mudar um pouco este cenário, faz-se necessário um novo olhar para a criança, compreender que ela é um ser ativo, capaz de criar, criticar, agir e sentir; mas para isso a instituição precisa oferecer propostas significativas para a criança.

Ao oferecer um programa de vivências lúdicas, modificando um pouco a rotina destas crianças, foi possível verificar que o convívio das crianças entre si, com outros objetos e espaços foi ampliado, o que pode auxiliar em seu desenvolvimento ${ }^{10,12}$; rompendo, mesmo que de forma discreta, a rotina rígida e uniforme em que as crianças estavam submetidas na instituição. Nas atividades lúdicas, as crianças não precisaram seguir o ritmo único da instituição; seus diferentes ritmos foram respeitados.
Nas aulas oferecidas, as crianças participaram de diferentes jogos, em um espaço grande e diferente do vivenciado em sala de aula, o que permitiu a vivência de diferentes habilidades motoras, bem como convívio social. Pôde-se observar que 10 dos 15 jogos propostos pelo programa, com o passar dos dias, passaram a ser solicitados pelas crianças ao professor e neles, as crianças participaram ativamente, sendo assim consideradas atividades molares ${ }^{12,16}$.

Estas atividades incluíam possibilidades de deslocar-se pelo espaço, enquanto que as três atividades sentadas em rodas, não se mostraram significativas para as crianças, pois não foram solicitadas ao longo do programa e quando oferecidas, as crianças mostravam desinteresse por elas. Provavelmente, isto ocorreu porque as crianças, ao ficarem muito tempo paradas dentro da instituição e no pouco tempo que dispunham para se deslocar e explorar livremente o espaço, preferiam fazê-lo; além disto, estas atividades propiciavam participação na elaboração de regras, vivências de papéis sociais e relacionamentos interpessoais, abrindo espaços para demonstração de demandas, recursos e disposições pessoais, de forma criativa.

As atividades que se destacaram no evento, nas quais houve bastante aderência das crianças, aconteceram na estação do Tarzan e o Zorro e na estação do Peter Pan. Algumas crianças, após o evento, pediram para realizar as atividades desta estação e foram observadas, simulando estar de posse do material usado na estação, a espada de jornal. Uma explicação para isso talvez seja porque as crianças tiveram mais "liberdade" de se expressarem nestas estações, pois as atividades foram realizadas com a proposta de solucionar problemas ou executar tarefas. Na estação do Passeio da Floresta, as crianças foram dirigidas o tempo todo por adultos, sobrando pouco espaço para exploração e criação de novas brincadeiras, ou seja, elas tiveram poucas possibilidades de livre expressão, As atividades desta estação foram consideradas moleculares, pois a crianças não permaneceram nela.

Os papéis sociais desempenhados pelas crianças estiveram relacionados com as atividades molares realizadas. Isto ocorreu nos papéis sociais em que as crianças representaram os personagens de história, aparecendo personagens de desenhos, jogador de futebol e representação de profissões de familiares da criança. Isto é importante para que elas apreendam formas de ação e funções pré-estabelecidas na sociedade, ao mesmo tempo em que experimentam o contraste entre suas expectativas ao realizar um determinado papel e os diferentes 
sentimentos trazidos por ocupar esta função, o que varia de acordo com os diferentes tratamentos que recebe das outras crianças quando isto ocorre. Este contraste auxilia na reflexão crítica sobre a organização da sociedade, contribuindo, também, para o desenvolvimento social ${ }^{9,11}$.

Verifica-se, também, que houve uma evolução no comportamento social, referente à aceitação de regras. Se várias crianças não queriam submeter-se às regras, nas primeiras aulas, com o tempo elas passaram a auxiliar na elaboração das mesmas e a respeitá-las. No entanto, isto parece estar ligado com o significado das atividades para elas, pois em uma das atividades do evento, as crianças voltaram a não se submeter às regras impostas e a se organizarem de forma diferente da solicitada, para explorar o espaço e brincar com os amigos. Assim, à medida que a atividade se torna significativa e que as regras são compreendidas e mudadas conforme a sugestão das crianças, estas aceitam e cumpremnas. Isto demonstra a importância de participar de jogos na escola, para aprender a aceitar e re-criar regras de convívio social.

Os jogos oferecidos tanto durante as aulas, quanto no evento, propiciaram a manifestação das principais emoções básicas do ser humano (alegria, tristeza, medo, surpresa e raiva), mostrando ser o jogo um espaço para que a criança possa vivenciar e aprender a lidar com suas emoções, ao mesmo tempo em que constrói relacionamentos interpessoais.

As relações pessoais se alteraram durante as aulas, quando as crianças ficaram mais próximas entre si, passando da simples observação à participação conjunta em atividades (díadas e tríadas de observação e participação conjunta). Através dos jogos e brincadeiras, as crianças foram estimuladas a resolver conflitos, questionar, relacionar e criar. Os desafios propostos levaram muitas crianças que, no início do programa, mostraram-se tímidas e inseguras, a ousarem mais e essas atitudes tornaram-nas parte do grupo, e não somente espectadores como no início.

No evento, muitas díadas de participação conjunta, observadas durante as aulas, foram mantidas, enquanto poucas foram as inter-relações sociais observadas com as demais crianças. Além de não terem relacionamentos interpessoais anteriores com as outras crianças, as crianças que participaram do programa de Educação Física conseguiram se integrar mais às atividades no evento, pois já haviam explorado o espaço e alguns materiais durante as aulas, o que facilitava o convívio entre si, enquanto que muitas crianças que não haviam participado do programa, não conseguiram se relacionar com as de- mais, por não saberem dividir e utilizar o material.

Entre as disposições pessoais observadas estava a curiosidade que levou várias crianças a terem iniciativa de participar nas atividades. Esta apareceu em relação aos materiais (principalmente o TNT durante as aulas) e no contato com novos personagens, no evento. Os TNT se destacaram pelas cores fortes e a leveza, ao serem lançados ao ar. Os tubos de papelão, também, tornaram-se objetos atrativos, por meio dos quais as crianças exploraram diversas formas de brincar.

Outra característica de interação, observada na disposição pessoal para iniciar-se na brincadeira e no jogo, foi a de engajar-se na atividade a convite dos colegas (demandas positivas), o que auxiliou na evolução das díadas e tríadas, propiciando, também, laços afetivos positivos na relação, também, encontrados no estudo de De Marco ${ }^{11}$.

Disposições disruptivas passivas também foram encontradas. Algumas vezes, as crianças se afastaram da atividade para assistir outros colegas que brincavam. Algumas crianças apresentaram disposição disruptiva ativa de comportamento impulsivo, ansioso e egocêntrico ao segurarem as bolas na atividade, não permitindo que outras crianças da equipe realizassem a tarefa. No início, a dificuldade em respeitar o material afastava algumas crianças do grupo, porém, com as aulas, estas atitudes foram desaparecendo.

No início do programa, os recursos pessoais negativos desencadearam comportamentos agressivos, como na disputa de materiais. Assim, ocorreram, as disposições desenvolvimentalmente disruptivas ${ }^{12}$ que promoveram impulsividade, explosividade e impaciência para perseguir metas em longo prazo e, com a dificuldade em controlar as emoções, algumas crianças se afastaram do grupo. Com o passar das aulas, percebeu-se um amadurecimento no controle das emoções e aquisição de recursos positivos em relação ao uso do material, além de relacionamentos mais fortes das crianças entre si, provocando o despertar de demandas positivas. $\mathrm{O}$ que mostra que estas atividades podem contribuir de maneira significativa na evolução das relações interpessoais destas crianças, criando espaço para que elas possam realizar atividades que lhes dêem prazer e, desta maneira, queiram convidar outras crianças para brincar.

Outro exemplo que pôde ser visto, durante o evento, quando, em uma das atividades, as crianças demonstraram disposições disruptivas, negando-se a realizar o que havia sido solicitado e convidando outras crianças a buscar alternativas de explorar o espaço e os equipamentos. Demandas negativas, tais 
como dificuldades em respeitar as regras propostas, ou lideranças negativas foram observadas por Machado e $\mathrm{Krebs}^{20}$ que dificultaram a realização das atividades. Percebe-se, assim, que ao mesmo tempo que a disposição disruptiva ocorreu, apareceram, também, demandas geradoras e que ambas estavam ligadas ao significado que a atividade proposta tinha para as crianças, o que indica, mais uma vez, a importância de se adequar as atividades às necessidades e aos desejos das crianças, de forma equilibrada.

\section{CONCLUSÃO}

A maioria das atividades apresentadas no programa adquiriu significado (tornaram-se atividades molares) através das aulas, sendo possível observar, no mesotempo, que as crianças passaram a requerer a realização das mesmas, engajando-se cada vez mais. Estas atividades incluíam possibilidades de deslocamento e exploração do espaço. Jogos em rodas sentada não foram solicitados pelas crianças, que aderiam pouco quando instadas a realizá-los. A manifestação de papéis sociais parece estar atrelada ao engajamento na atividade, porque foram nas atividades molares que as crianças desempenharam o maior número de papéis sociais.

É possível inferir que houve evolução nos relacionamentos interpessoais, dado que no mesotempo houve um aumento no número de relacionamentos interpessoais e diádas/tríadas de observação tornaram-se em díadas e tríadas de participação conjunta, ou seja, as crianças passaram a realizar com frequência, atividades em duplas ou trios, formados espontaneamente. Estas díadas e tríadas também apareceram no mesossistema, isto é, mantiveram-se nos dois ambientes onde a criança foi analisada.

Parece ter havido, também, aquisição de controle emocional, verificada através da mudança na forma como a emoção foi demonstrada no mesotempo, onde no início ocorriam exacerbações emocionais com agressões, choros, gritos e até mesmo tentativas de agressão física entre as crianças e, com as aulas, estas passaram ser expressadas de maneira mais suave, sem estas manifestações agressivas, o que aumentou a participação da criança no grupo.

Atributos pessoais foram utilizados pelas crianças em momentos em que desejavam participar, efetivamente, das atividades e também, naqueles em que queriam substituir as atividades por outras, ou desejavam se impor ao amigo para conseguir dele uma determinada atitude ou pegar o material que com ele estava. A construção de regras junto com as crianças, que aconteceu paulatinamente, durante o programa, auxiliou na conduta social, possibilitando adequações de espaço, tempo, uso do material e conduta durante os jogos.

\section{REFERÊNCIAS BIBLIOGRÁFICAS}

1. Silva JVP, Tolocka RE, Marcellino NC. Lazer Infantil: direitos legais, transformações sociais e implicações ao crescimento e habilidades motoras básicas. Licere 2006;9(1):81-96.

2. Batista R. A rotina no dia-a-dia da creche: entre o proposto e o vivido. [Dissertação de Mestrado - Programa de Pós Graduação em Educação]. Florianópolis: Universidade Federal de Santa Catarina, 1998.

3. Ozer EJ, The effects of school gardens on students and schools: conceptualization and considerations for maximizing healthy development. Health Educ Behav 2007;34(6):846-863.

4. Lima AB, Bhering E. Um estudo sobre creches como ambiente de desenvolvimento. Cad Pesqu 2006;36(129):573-596.

5. Bronfenbrenner U, Evans GW. Developmental science in the 21 century: Emerging questions, theoretical models, research designs and empirical findings. Social Development 2000;9(1):115-125.

6. Bronfenbrenner U; Morris, P. A. The Ecology of Developmental Process. In: Pedro, J. G. editor. Stress and Violence in Childhood and Youth. Faculdade de Medicina, Universidade de Lisboa, Lisboa, 1999. p.21-95.

7. Bronfenbrenner U. The bioecological theory of human development. In: Bronfenbrenner, U. editor Making human beings human: Bioecological perspectives on human development. Sage Publication, Inc, 2005.

8. Bronfenbrenner U, Morris PA. The Bioecological Model of Human Development. In: Damon W, Lerner RM. Editors. Handbook of Child Psychology: Theoretical Models of Human Development. 2006. p.793-825.

9. Krebs RJ. Proximal processes as the primary engines of development. Int J Sport Psychol 2009;40(1):219-228.

10. Krebs RJ, Copetti F, Serpa S, Araújo D. Disposições pessoais de tenistas jovens: um estudo fundamentado na teoria Bioecológica de Bronfenbrenner. Rev Bras Psicol Esporte 2008;2(2):1-24.

11. Krebs RJ. Bronfenbrenner's Bioecological Theory of Human Development and the process of development of sports talent. Int J Sport Psychol 2009;40(1):108-135.

12. Ramalho MHS. O recreio pré-escolar e a motricidade infantil na perspectiva da teoria da ecologia do desenvolvimento humano. [Tese de Doutorado - Programa de PósGraduação em Ciência do Movimento Humano]. Santa Maria (RS): Universidade Federal de Santa Maria; 1996.

13. De Marco M. Manifestações emocionais em atividades motoras de crianças de 5 a 6 anos de idade da Educação Infantil. [Dissertação de Mestrado - Programa de Pós Graduação em Educação Física]. Piracicaba (SP): Universidade Metodista de Piracicaba; 2006.

14. Eisenmann JC, Gentile DA, Welk GJ, Callahan R, Strickland S, Walsh M, et al. Switch: rationale, design, and implementation of a community, school, and family-based intervention to modify behaviors related to childhood obesity. BMC Public Health 2008;29(8):223-243. 
15. Mendoza JA, Zimmerman FJ, Christakis DA. Television viewing, computer use, obesity, and adiposity in US preschool children. Int J Behav Nutr Phys Act 2007; 25(4):44-54.

16. Berleze A, Haeffner LSB, Valentini NC. Desempenho motor de crianças obesas: uma investigação do processo e produto de habilidades motoras fundamentais. Rev Bras Cineantropom Desempenho Hum 2007; 9(2):134-144.

17. Bigotti S, Tolocka RE. Desenvolvimento motor, gênero e medidas antropométricas em crianças na infância avançada. Temas Desenvolv 2005;14(84):49-56.

18. Gomes R. A análise de dados em pesquisa qualitativa. In: Minayo Mcs, Cruz Neto O, Gomes R. Organizador. Pesquisa social: teoria, método e criatividade. $21 \mathrm{ed}$. Petrópolis-RJ: Vozes, 2002.p. 45-60.

19. Freire JB, Goda C. Fabricando: as oficinas do jogo como proposta educacional nas séries iniciais do ensino fundamental. Movimento 2008;14(1):111-134.
20. Machado Z, Krebs RJ. Crescimento físico de escolares da Ilha de Santa Catarina. Rev Bras Cineantropom Desempenho Hum 2001;3(1): 7-17.

\section{Endereço para correspondência}

Rute Estanislava Tolocka

Universidade Metodista de Piracicaba. Curso de Mestrado em Educação Física. Caixa Postal 68; Campus Taquaral - Rodovia do Açúcar Km 156. CEP: 13400-911- Piracicaba. SP. Brasil.

Email: tkiva05@yahoo.com.br 